\title{
Corrigendum: Broadband magnetometry and temperature sensing with a light-trapping diamond waveguide
}

Hannah Clevenson, Matthew E. Trusheim, Carson Teale, Tim Schröder, Danielle Braje and Dirk Englund

Nature Physics 11, 393-397 (2015); published online 6 April 2015; corrected after print 3 September 2015.

The version of this Letter originally published contained an error in the interpretation of the system noise floor resulting from lock-in amplifier filtering. Accordingly, Figs 4 and 5 (below) and the corresponding magnetic field sensitivity in the text have now been corrected in the online versions of the Letter.

\section{Figure 4}

a

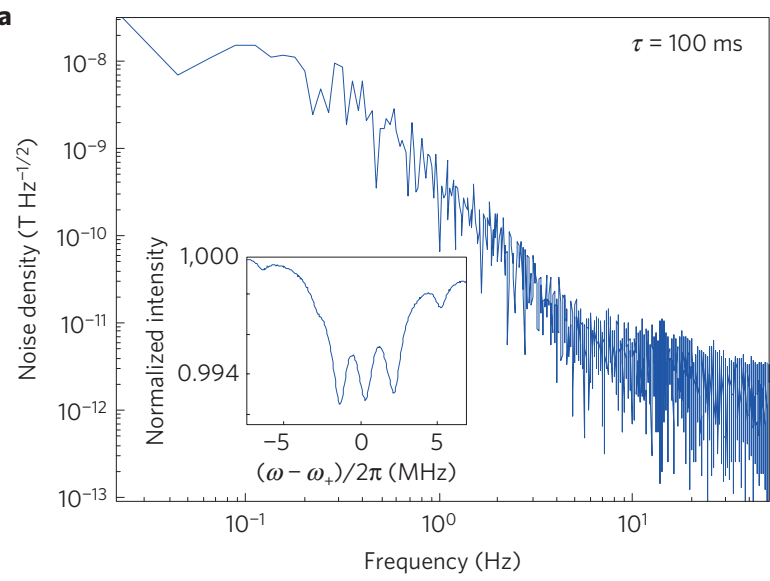

Figure 5

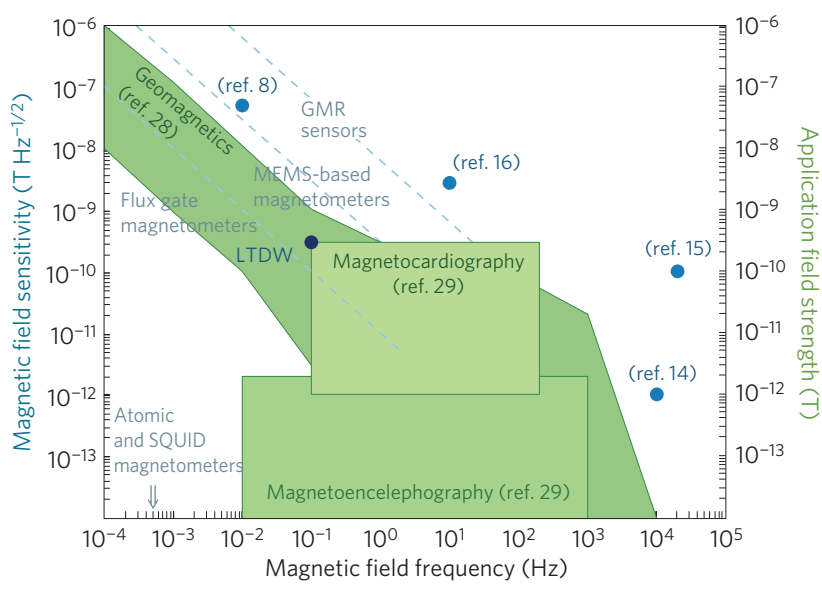

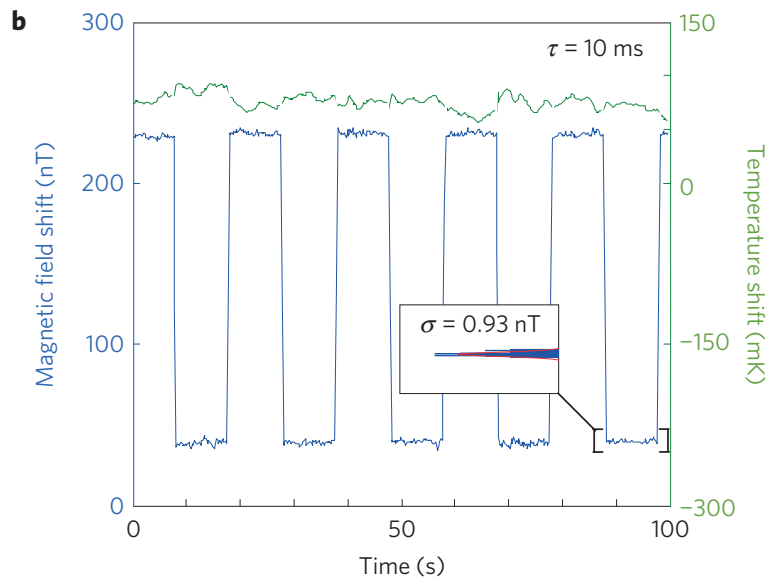

